\title{
Brotações adventícias de abacaxizeiro ornamental sob o efeito de benzilaminopurina, ácido naftalenoacético e períodos de subcultivo
}

\author{
Maria do Desterro Mendes Santos ${ }^{(1)}$, Dalva Graciano Ribeiro(1) e Antonio Carlos Torres $^{(2)}$
}

(1)Universidade de Brasília, Departamento de Botânica, Caixa Postal 04457, CEP 70919-970 Brasília, DF. E-mail: maria@cnph.embrapa.br, graciano@unb.br ${ }^{(2)}$ Embrapa Hortaliças, Caixa Postal 218, CEP 70359-970 Gama, DF. E-mail: torres@cnph.embrapa.br

Resumo - O objetivo deste trabalho foi avaliar os efeitos da adição de benzilaminopurina (BAP), em combinação com o ácido naftalenoacético (ANA), e dos períodos de subcultivo, na formação de brotações in vitro de abacaxizeiro ornamental. O meio básico líquido consistiu de sais minerais MS e vitaminas. O delineamento experimental utilizado foi o inteiramente casualizado, em esquema fatorial $6 \times 2 \times 4$, com seis concentrações de BAP $\left(0,0,125,0,25,0,5,1\right.$ e $\left.2 \mathrm{mg} \mathrm{L}^{-1}\right)$ e duas de ANA $\left(0\right.$ e $\left.0,1 \mathrm{mg} \mathrm{L}^{-1}\right)$, e quatro períodos de subcultivo (30, 60, 90 e 120 dias). Os explantes consistiram de brotações individuais de $1 \mathrm{~cm}$ de comprimento, oriundas da cultura in vitro. A formação de novas brotações foi observada em meio suplementado com BAP, em todos os períodos de subcultivo. O maior número médio de brotos por explante foi obtido em meio com a concentração de $1,2 \mathrm{mg} \mathrm{L}^{-1}$ de BAP e 120 dias de subcultivo.

Termos para indexação: Ananas comosus, cultivo in vitro, micropropagação.

\section{Adventitious shoot of ornamental pineapple under benzylaminopurine, naphthalene acetic acid and subculture period effect}

\begin{abstract}
The objective of this work was to evaluate the effect of benzylaminopurine (BAP) additions, in combination with naphthaleneacetic acid (NAA), and of subcultures periods on in vitro shoot formation of ornamental pineapple. The basal liquid medium consisted of MS salts and vitamins. The experiment was a completely randomized design, in a factorial arrangement $6 \times 2 \times 4$, with six concentrations of BAP $(0,0.125$, $0.25,0.5,1$, e $\left.2 \mathrm{mg} \mathrm{L}^{-1}\right)$ and two of NAA $\left(0\right.$ and $\left.0.1 \mathrm{mg} \mathrm{L}^{-1}\right)$, and four subculturing periods $(30,60,90 \mathrm{e}$ 120 days). The explants consisted of individualized shoots with $1 \mathrm{~cm}$ length from in vitro cultures. Shoot formation was observed in medium supplemented with BAP in all subculturing periods. The greatest average number of shoots per explant was obtained with BAP concentration of $1.2 \mathrm{mg} \mathrm{L}^{-1}$ and 120 days of subcultive.
\end{abstract}

Index terms: Ananas comosus, in vitro culture, micropropagation.

\section{Introdução}

O abacaxizeiro ornamental (Ananas comosus var. bracteatus (Lindl.) Coppens D’Eeckenbrugge \& Leal, 2003) é uma planta monocotiledônea da família Bromeliaceae(Collins, 1960; Coppens D'Eeckenbrugge \& Leal, 2003), com grande potencial ornamental, que vem sendo muito apreciada no mercado interno e externo de flores (Souza et al., 2004).

No Estado do Ceará, foi relatada a produção de 12 mil hastes florais por mês, que eram exportadas para a Alemanha, Holanda e Estados Unidos (Correia et al., 2000). Essa espécie propaga-se vegetativamente. Assim, pode haver acúmulo de agentes causais de doenças importantes economicamente, que são transmitidas e intensificadas de um ciclo de produção a outro, via mudas contaminadas. Entre as principais doenças estão as causadas por fungos. Há demanda do setor produtivo por mudas de plantas ornamentais de melhor qualidade fitossanitária e, principalmente, isentas de fusariose (Reinhardt \& Cunha, 1999). Além disso, em condições naturais, cada planta produz até 10 mudas por ano, e a demanda por mudas sadias é um fator limitante à expansão da cultura (Correia et al., 2000).

Zepeda \& Sagawa (1981) estudaram o abacaxizeiro e estimaram que uma gema axilar em cultura pode produzir 5 mil plantas, ao final de um ano. Na cultura de tecidos de Ananas sp., uma grande variedade de formulações de meio tem sido usada. Isto reflete a 
exigência específica dos genótipos, partes da planta que têm sido cultivadas (explantes) e os objetivos do trabalho. Os protocolos da cultura de tecidos nesse gênero foram estabelecidos, predominantemente, para A. comosus var. comosus (Mathews \& Rangan, 1979; Dewald et al., 1988; Escalona, 1999; Guerra et al., 1999; Silva et al., 2002; Tamaki et al., 2007). Entretanto, são poucos os trabalhos de micropropagação de $A$. comosus var. bracteatus (Carvalho et al., 2005; Costa \& Zaffari, 2005), e questões referentes às respostas morfogenéticas de gemas axilares, em meio de multiplicação com diferentes períodos de subcultivos, precisam ser esclarecidas.

O objetivo deste trabalho foi avaliar os efeitos da adição de benzilaminopurina (BAP), em combinação com ácido alfa-naftalenoacético (ANA), e de períodos de subcultivos, na formação de brotações in vitro de abacaxizeiro ornamental.

\section{Material e Métodos}

O experimento foi realizado no Laboratório de Biologia Celular, da Embrapa Hortaliças, em Brasília, DF, de outubro de 2006 a dezembro de 2007.

Foram utilizadas como fonte de explantes brotações individualizadas com aproximadamente $1 \mathrm{~cm}$ de comprimento, com dominância apical, estabelecidas a partir da cultura de gemas axilares (oriundas de mudas tipo coroa, excisadas de plantas com 24 meses de idade, desenvolvidas em casa de vegetação). Os explantes foram cultivados em meio básico líquido com sais minerais MS (Murashige \& Skoog, 1962), 3\% de sacarose; $0,1 \mathrm{mg} \mathrm{L}^{-1}$ de tiamina. $\mathrm{HCl} ; 0,05 \mathrm{mg} \mathrm{L}^{-1} \mathrm{de}$ piridoxina. $\mathrm{HCl} ; 0,05 \mathrm{mg} \mathrm{L}^{-1}$ de ácido nicotínico; e $2 \mathrm{mg} \mathrm{L}^{-1}$ de glicina.

$\mathrm{O}$ delineamento experimental utilizado foi $\mathrm{o}$ inteiramente casualizado, em esquema fatorial $6 \times 2 \times 4$, referente a seis concentrações de BAP, duas concentrações de ANA e quatro períodos de subcultivos. Ao meio básico foram adicionadas seis concentrações de BAP $(0,0,125,0,25,0,5,1$ e $2 \mathrm{mg} \mathrm{L}^{-1}$ ), em combinação com duas concentrações de ANA ( 0 e $\left.0,1 \mathrm{mg} \mathrm{L}^{-1}\right)$, em quatro períodos de subcultivos (30, 60, 90 e 120 dias). $\mathrm{O}$ pH dos meios foi ajustado a 5,7. Foram utilizadas nove repetições por tratamento, e cada parcela foi constituída por um explante. Inicialmente, os explantes foram colocados em frascos de $250 \mathrm{~mL}$ de capacidade, com $40 \mathrm{~mL}$ de meio. No segundo subcultivo, os propágulos foram transferidos para frascos idênticos, com meio recémpreparado. No terceiro e quarto subcultivos, foram utilizados frascos de 1.000 e $2.000 \mathrm{~mL}$, respectivamente com 100 e $150 \mathrm{~mL}$ de meio. As culturas foram mantidas em sala de crescimento sob fotoperído de 16 horas, com densidade de fluxo de fótons de $32 \mu \mathrm{mol} \mathrm{m}{ }^{-2} \mathrm{~s}^{-1}$, a $27 \pm 2^{\circ} \mathrm{C}$. Em cada subcultivo, foram determinados o número e a massa de matéria fresca das brotações formadas por explante.

Os dados foram transformados em $\log (\mathrm{x}+1)$, e as análises estatísticas foram realizadas com o SAS (SAS Institute, 1998) e o SISVAR versão 3.01 (Ferreira, 2000). Aplicou-se a análise de regressão polinomial até segundo grau, para avaliar o efeito da concentração do hormônio sobre o número de brotos em cada meio de cultivo, subcultivo e, também, para avaliar a variação do número de brotos em razão do subcultivo para cada concentração de hormônio nos diferentes meios.

\section{Resultados e Discussão}

Houve efeito significativo das diferentes concentrações de BAP e de ANA e dos períodos de subcultivo nas características número e massa de matéria fresca das brotações do abacaxizeiro (Tabela 1). Também houve efeito das interações duplas. Apesar de as interações triplas serem significativas somente quanto à massa de matéria fresca, foi necessário fazer seu desdobramento para se verificarem as possíveis significâncias.

Tabela 1. Análise de variância do número de brotos e da massa de matéria fresca de brotações (MMFB) de Ananas comosus var. bracteatus, em razão das concentrações de BAP e de ANA e dos períodos de subcultivo.

\begin{tabular}{lrrr}
\hline Fonte de variação & GL & \multicolumn{2}{c}{ Quadrado médio } \\
\cline { 3 - 4 } & \multicolumn{3}{c}{$\begin{array}{c}\text { Número de } \\
\text { brotos }\end{array}$} \\
\hline Concentração de BAP (CB) & 5 & $29,5017^{*}$ & $6,7029^{*}$ \\
Concentração de ANA (CA) & 1 & $3,4569^{*}$ & $1,3643^{*}$ \\
Cultivo (C) & 3 & $29,3200^{*}$ & $31,0706^{*}$ \\
CBxCA & 5 & $0,7213^{*}$ & $0,3850^{*}$ \\
CBxC & 15 & $1,0355^{*}$ & $0,6531^{*}$ \\
CAxC & 3 & $0,2919^{*}$ & $0,1380^{*}$ \\
CBxCAxC & 15 & $0,0845^{\text {ns }}$ & $0,0882^{*}$ \\
Resíduo & 384 & 0,0756 & 0,0234 \\
\hline Média ${ }^{(1)}$ & & 1,59 & 1,25 \\
CV $(\%)$ & & 17,30 & 12,26 \\
\hline
\end{tabular}

${ }^{(1)}$ Médias transformadas em $\log (\mathrm{x}+1)$. ${ }^{\mathrm{n}} \mathrm{Não}$-significativo. *Significativo a $5 \%$ de probabilidade. 
Houve relação quadrática entre o número de brotações formadas por explante e a concentração de BAP em combinação com as concentrações de ANA, em todos os períodos de subcultivo (Figuras 1 e 2). $\mathrm{O}$ meio nutritivo sem BAP foi considerado ineficiente para a multiplicação de abacaxizeiro ornamental, pela formação de baixo número de brotações por explante. Resultados semelhantes foram obtidos por Tamaki et al. (2007), com cultivo in vitro do abacaxizeiro comercial, em meio desprovido de reguladores de crescimento, que produziu 50 plantas a partir de uma gema introduzida, no período de 12 meses.

No presente trabalho, a adição de BAP foi necessária para a indução satisfatória de brotações in vitro, em explantes dessa espécie. As citocininas têm ação em diversos processos de desenvolvimento da planta, inclusive divisão celular e diferenciação de culturas celulares (Redig et al., 1996), respostas morfogenéticas (Centeno et al., 1996) e desenvolvimento de órgãos (Auer \& Cohen, 1993). Estudos sobre micropropagação de espécies do gênero Ananas têm usado a citocinina BAP na indução de brotações, por apresentar resultados eficientes, principalmente, em Ananas comosus (Escalona et al., 1999; Guerra et al., 1999; Cruz, 2000; Almeida et al., 2002; Firoozabady \& Gutterson, 2003), Ananas lucidus (Borges et al., 2003) e Ananas bracteatus $\mathrm{cv}$. striatus (Costa \& Zaffari, 2005).

Estimou-se que o maior número de brotações por explante, nos períodos de subcultivo de 30 e 60 dias, foi alcançado com a utilização da concentração de $1,17 \mathrm{mg} \mathrm{L}^{-1}$ de BAP, tendo-se obtido, respectivamente, 14,8 e 69,8 brotações; aos 90 e 120 dias, foram observados os máximos de 256,7 e 872,2 brotações, respectivamente, com a concentração de $1,2 \mathrm{mg} \mathrm{L}^{-1}$ de BAP. A concentração de BAP superior a $1,2 \mathrm{mg} \mathrm{L}^{-1}$ reduziria o número de brotações em todos os períodos de subcultivo (Figura 1). O aumento do número de brotações, em períodos sucessivos de subcultivo, foi constatado porAlmeida etal.(2002)em Ananas comosus cv. Pérola. Esses autores obtiveram 2.013,5 brotações, no quinto período de subcultivo (20 semanas), em meio líquido suplementado com $1,5 \mathrm{mg} \mathrm{L}^{-1}$ de BAP. Entretanto, em meio sólido, Silva et al. (2002) obtiveram o máximo de 7,5 brotos, maiores que $1 \mathrm{~cm}$, por explante, com a concentração de $2,52 \mathrm{mg} \mathrm{L}^{-1}$ de BAP, em 120 dias de cultivo, na cultivar Primavera, tendo usado tubos de ensaio como recipiente. Essa discrepância de resultados da literatura pode ser explicada pela formulação de meio (sólido ou líquido), recipiente utilizado para estabelecimento das culturas, período de subcultivo, genótipo e método utilizado em cada estudo. Entre as vantagens do uso do meio de cultura líquido se incluem: a maior homogeneidade, que permite maior velocidade de difusão (Costa \& Zaffari, 2005) e absorção mais eficiente de nutrientes para os tecidos (Escalona et al., 1999; Costa \& Zaffari, 2005); e o menor custo em seu preparo (Escalona et al., 1999).

Em meio suplementado com BAP e com $0,1 \mathrm{mg} \mathrm{L}^{-1}$ de ANA, inferiu-se que o ponto máximo para número de brotações nos subcultivos de 30 e 60 dias correspondeu, respectivamente, às concentrações de 0,7 e $1,2 \mathrm{mg} \mathrm{L}^{-1}$ de BAP, tendo-se obtido, respectivamente, 25,6 e 89,4 brotos por explante. Nos subcultivos de 90 e 120 dias, o máximo de brotações estimado foi de 306,6 e 730,7, com as concentrações de 1,2 e $1,4 \mathrm{mg} \mathrm{L}^{-1}$ de BAP, respectivamente (Figura 2). Essa concentração hormonal ótima para maximizar o desenvolvimento,
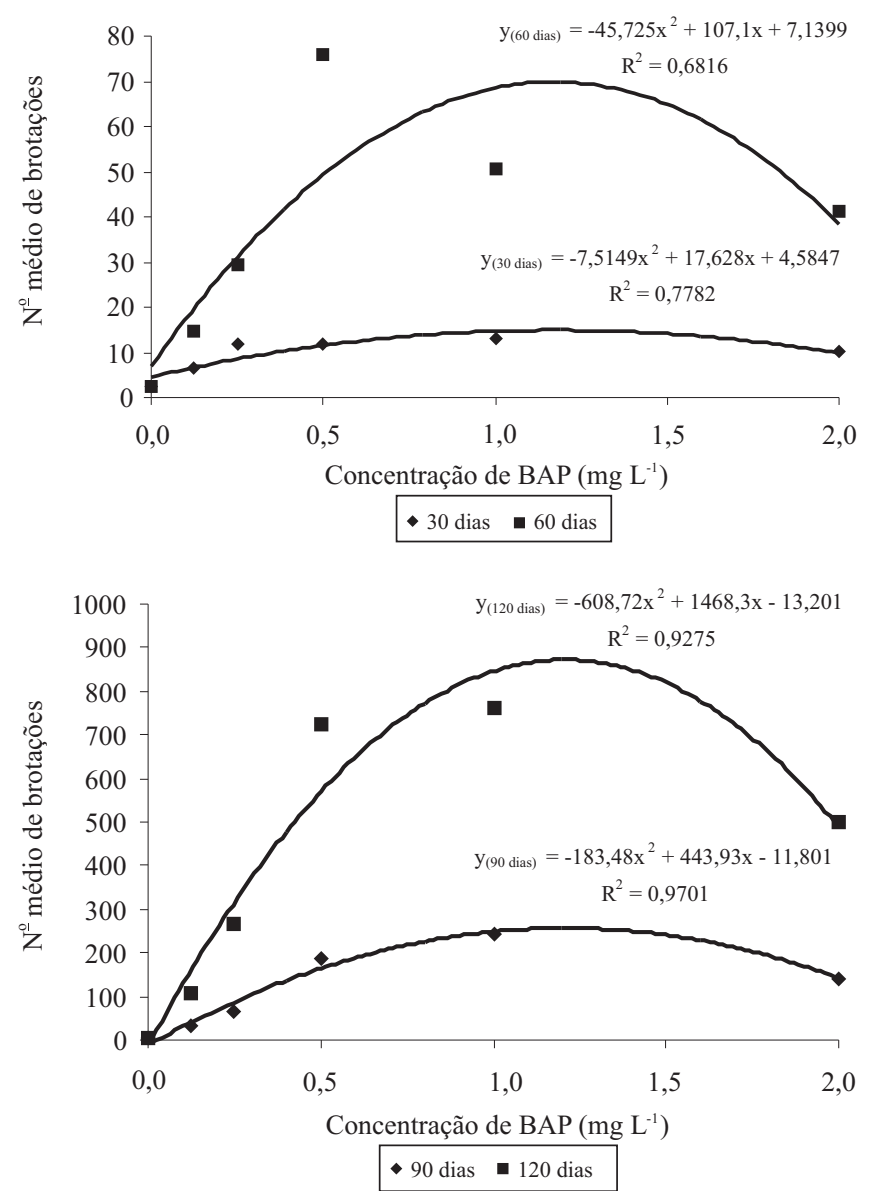

Figura 1. Número de brotações em explantes de Ananas comosus var. bracteatus, em função da concentração de BAP, na ausência de ANA, nos períodos de subcultivo de $30,60,90$ e 120 dias. 
acima da qual há um efeito inibitório, tem sido observada em trabalhos in vitro com Gymnocalycium baldianum e Mammillaria bocasana (Pasqual \& Hoshica, 1992), Ananas comosus (Silva et al., 2002), Ficus carica (Fráguas et al., 2004), Malus domestica (Erig \& Schuch, 2005) e Rubus sp. (Villa et al., 2005).

Nos subcultivos de 30 e 60 dias, a proliferação de brotações foi superior na presença de ANA. Aos 90 dias de subcultivo, o número de brotações formadas foi idêntico tanto na presença quanto na ausência de ANA. Entretanto, no subcultivo de 120 dias, a ausência de ANA induziu maior número de brotações por explante. Possivelmente, a partir dos 90 dias, a adição de ANA tem efeito inibitório na formação de brotações, em razão do efeito residual dessa substância reguladora de crescimento nos propágulos produzidos. A utilização de BAP em combinação com ANA tem sido relatada
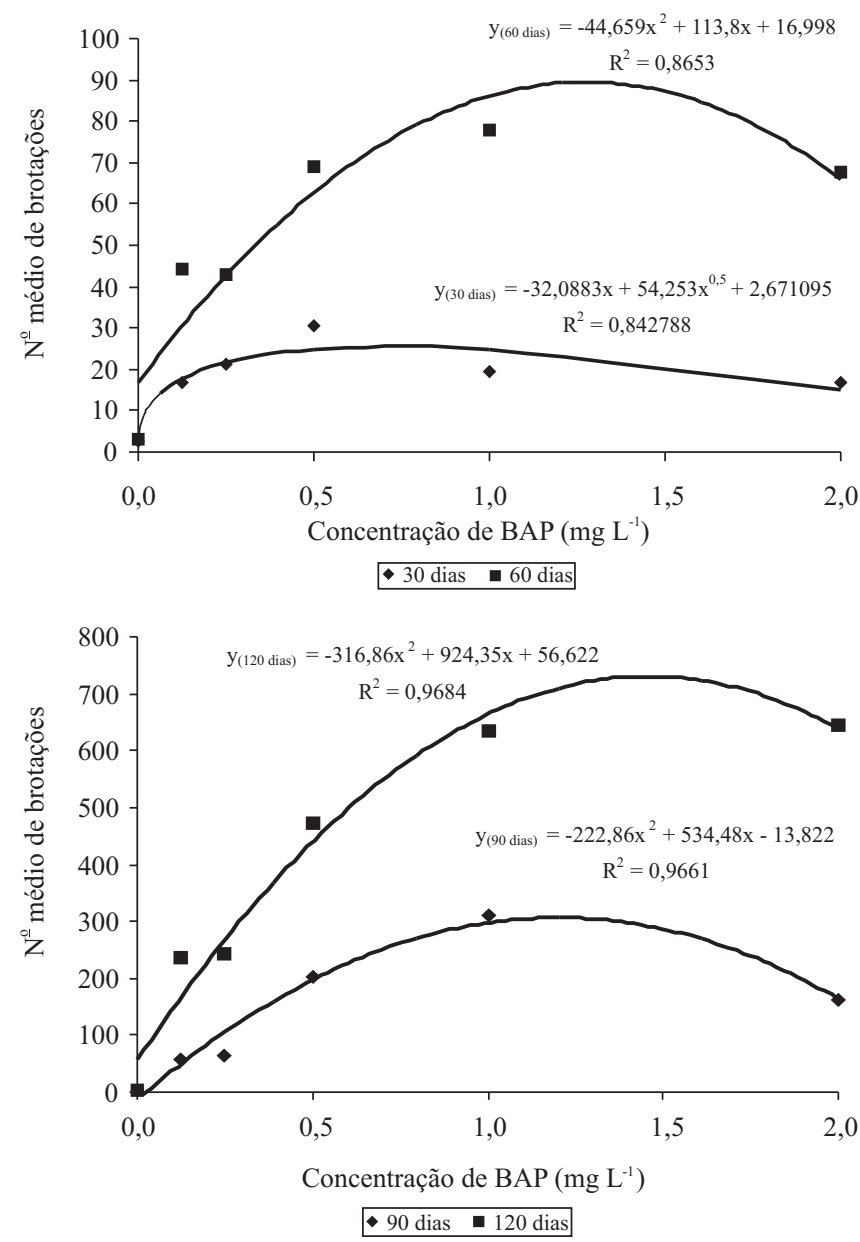

Figura 2. Número de brotações em explantes de Ananas comosus var. bracteatus, em função das concentrações de BAP e de ANA $\left(0,1 \mathrm{mg} \mathrm{L}^{-1}\right)$, nos períodos de subcultivo de 30, 60, 90 e 120 dias. em trabalhos de micropropagação de espécies do gênero Ananas (Escalona et al., 1999; Guerra et al., 1999; Borges et al., 2003; Firoozabady \& Gutterson, 2003; Barboza et al., 2004; Costa \& Zaffari, 2005). Entretanto, o balanço entre BAP e ANA é dependente do genótipo, na maximização da resposta morfogenética. Barboza et al. (2004) compararam a taxa de multiplicação do híbrido PExSC-52 à da variedade Smooth Cayenne, em meio com BAP suplementado ou não com ANA. Em meio com $2 \mathrm{mg} \mathrm{L}^{-1}$ de BAP, o híbrido apresentou taxa de multiplicação mais elevada em relação à da 'Smooth Cayenne'. Com a adição de $2 \mathrm{mg} \mathrm{L}^{-1}$ de BAP $+2 \mathrm{mg} \mathrm{L}^{-1}$ de ANA, a cultivar Smooth Cayenne melhorou a taxa de multiplicação, enquanto o híbrido sofreu redução nessa variável. Variação no número de brotações formadas, atribuídas a diferentes genótipos, tem sido relatada na literatura (Dewald et al., 1988; Guerra et al., 1999).

No sistema descrito no presente trabalho (biorreatores estacionários), não foi observada vitrificação das brotações produzidas. O que limita o uso de biorreatores, na cultura de tecidos de plantas, é o aparecimento de propágulos vitrificados, que resultam em morfogênese anormal em meio líquido (Ziv, 1991).

Aos 30 dias de subcultivo, não houve diferença entre as concentrações de BAP tanto em presença quanto ausência de ANA, na variável massa de matéria fresca. A concentração de BAP afetou a produção de biomassa da parte aérea nos subcultivos de 60,90 e 120 dias, e apresentou relação quadrática, em meio com e sem ANA (Figuras 3 e 4). Aos 60 dias, em meio desprovido de ANA, estimou-se a maior massa de matéria fresca de

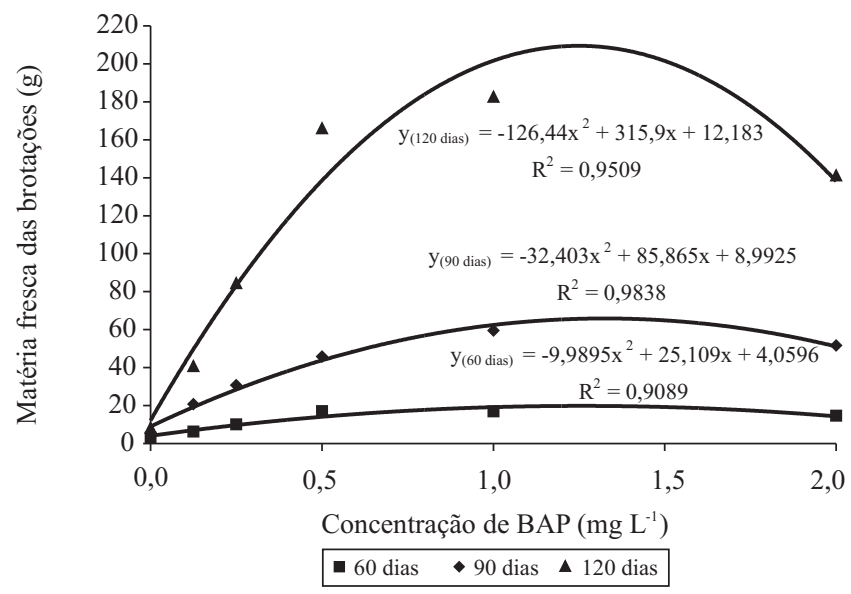

Figura 3. Massa de matéria fresca de brotações de Ananas comosus var. bracteatus, em função da concentração de BAP, na ausência de ANA, nos períodos de subcultivo de 60,90 e 120 dias. 
brotações - 19,8 $\mathrm{g}$ - com a concentração de $1,2 \mathrm{mg} \mathrm{L}^{-1}$ de BAP. Nos subcultivos de 90 e 120 dias, os máximos de biomassa de 65,8 e 209,4 g, respectivamente, foram estimados com a concentração de $1,3 \mathrm{mg} \mathrm{L}^{-1}$ de BAP. Concentrações de BAP superiores a $1,3 \mathrm{mg} \mathrm{L}^{-1}$ tendem a reduzir a produção de biomassa (Figura 3 ).

Também foi observado que a inclusão de ANA no meio de cultura propiciou, aos 60, 90 e 120 dias de subcultivo, a estimativa de produção máxima de biomassa, de 19,6, 97,9 e 178,7 g, respectivamente com $0,9,1,1$ e $1,2 \mathrm{mg} \mathrm{L}^{-1}$ de BAP (Figura 4). Esse parâmetro estima a habilidade do sistema caulinar de se desenvolver in vitro. Resultados semelhantes foram relatados por Villa et al. (2005), em trabalho com amoreira-preta, em que a massa da matéria fresca atingiu o máximo com a utilização de $1 \mathrm{mg} \mathrm{L}^{-1}$ de BAP e, a partir dessa concentração, o BAP passou a inibir o desenvolvimento das plantas in vitro, com decréscimo na produção de biomassa total. Com esse resultado,
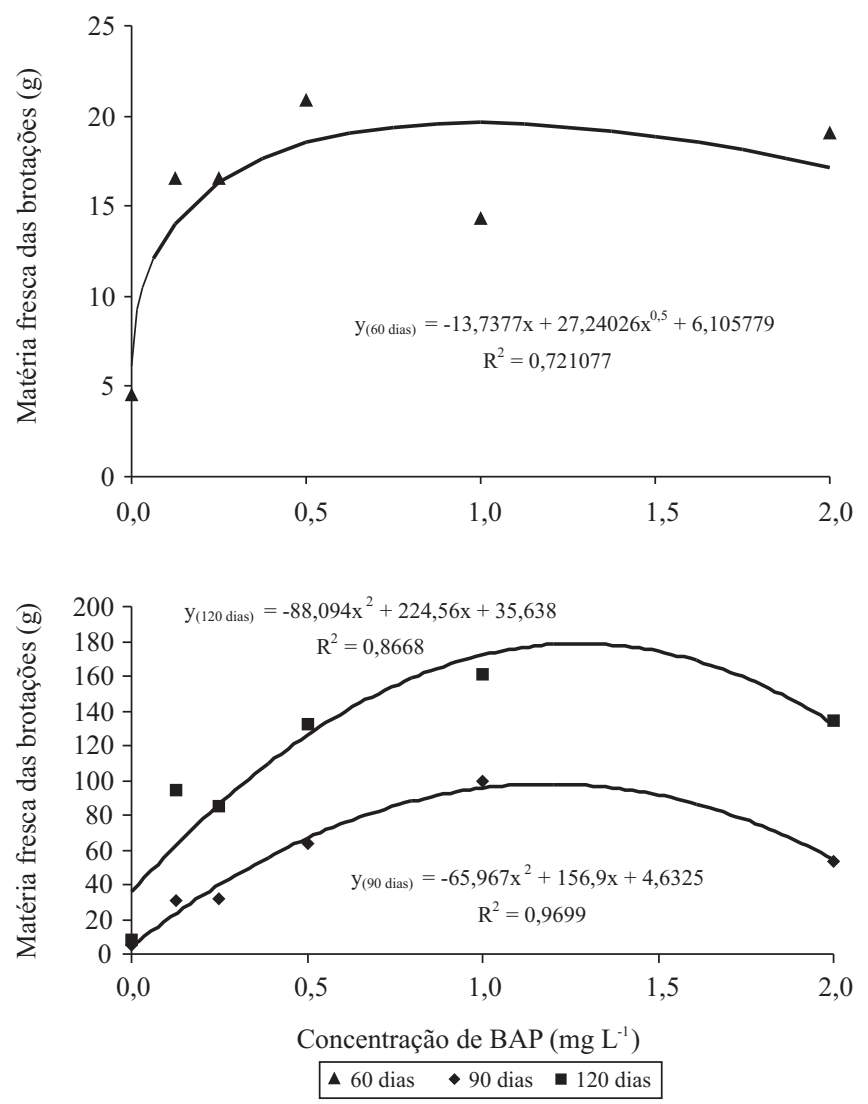

Figura 4. Massa de matéria fresca de brotações, em explantes de Ananas comosus var. bracteatus, em função das concentrações de BAP e de ANA $\left(0,1 \mathrm{mg} \mathrm{L}^{-1}\right)$, nos períodos de subcultivo de 60, 90 e 120 dias. infere-se a importância do balanço hormonal entre auxina e citocinina, no controle da proliferação de brotações em explantes de abacaxizeiro ornamental, conforme estabelecido por Skoog \& Miller (1957) e confirmado por outros autores em estudos de espécies do gênero Ananas (Dewald et al., 1988; Guerra et al., 1999; Barboza et al., 2004).

\section{Conclusões}

1. A propagação de Ananas comosus var. bracteatus, a partir de brotações obtidas in vitro, em formulação MS líquida suplementada com BAP, é satisfatória.

2. A concentração de $1,2 \mathrm{mg} \mathrm{L}^{-1}$ de $\mathrm{BAP}$, em subcultivos mensais, aos 120 dias de cultura, proporciona a melhor resposta para a multiplicação in vitro.

3. A concentração de $0,1 \mathrm{mg} \mathrm{L}^{-1}$ de ANA apresenta efeito sinergético com BAP, na formação de brotações nos subcultivos de 30 e 60 dias, e é inibitório aos subcultivos de 90 e 120 dias.

\section{Referências}

ALMEIDA, W.A.B. de; SANTANA, G.S.; RODRIGUEZ, A.P.M.; COSTA, M.A.P. de C. Optimization of a protocol for the micropropagation of pineapple. Revista Brasileira de Fruticultura, v.24, p.296-300, 2002.

AUER, C.A.; COHEN, J.D. Identification of a benzyladenine disaccharide conjugate produced during shoot organogenesis in Petunia leaf explants. Plant Physiology, v.102, p.541-545, 1993.

BARBOZA, S.B.S.C.; CALDAS, L.S.; SOUZA, L.A.C. Micropropagação do híbrido PExSC-52 e da cultivar Smooth Cayenne de abacaxizeiro. Pesquisa Agropecuária Brasileira, v.39, p.725-733, 2004.

BORGES, N.S.S.; CORREIA, D.; ROSSETTI, A.G. Influência do meio bifásico na multiplicação de gemas e no alongamento de brotos in vitro de Ananas lucidus Miller. Revista Brasileira de Horticultura Ornamental, v.9, p.37-44, 2003.

CARVALHO, A.C.P.P. de; BRAGA, E.P.; SANTOS, M.R.A. dos; MORAIS, J.P.S. Micropropagação de abacaxizeiro ornamental (Ananas comosus var. bracteatus) por meio da indução ao estiolamento e regeneração de plântulas. Revista Brasileira de Horticultura Ornamental, v.11, p.121-126, 2005.

CENTENO, M.L.; RODRÍGUEZ, A.; FEITO, I.; FERNÁNDEZ, B. Relationship between endogenous auxin and cytokinin levels and the morphogenic responses in Actinidia deliciosa tissue cultures. Plant Cell Reports, v.16, p.58-62, 1996.

COLLINS, J.L. The pineapple: botany, cultivation, and utilization. London: Leonard Hills, 1960. 294p.

COPPENS d'EeCKenBRUGGE, G.; LEAL, F. Morphology, anatomy and taxonomy. In: BARTHOLOMEW, D.P.; PAULL, 
R.E.; ROHRBACH, K.G. The pineapple: botany, production, and uses. New York: CAB International, 2003. p.13-32.

CORREIA, D.; RIBEIRO, K.A.; ROSSETI, A.G.; SILVEIRA, M.R.S. da. Efeito do ácido indol butírico e do carvão ativado no enraizamento in vitro de abacaxi ornamental (Ananas lucidus Miller). Fortaleza: Embrapa Agroindústria Tropical, 2000. 3p.

COSTA, T. da; ZAFFARI, G.R. Micropropagação de Ananas bracteatus (Schultz) var. striatus Hort. Revista Brasileira de Horticultura Ornamental, v.11, p.109-113, 2005.

CRUZ, A.R.R. Micropropagação de oito genótipos de abacaxizeiro (Ananas comosus (L.) Merril.). 2000. 69p. Dissertação (Mestrado) - Universidade de Brasília, Brasília.

DEWALD, M.G.; MOORE, G.A.; SHERMAN, W.B.; EVANS, M.H. Production of pineapple plants in vitro. Plant Cell Reports, v.7, p.535-537, 1988.

ERIG, A.C.; SCHUCH, M.W. Morfogênese in vitro de brotos de macieira (Malus domestica Borkh.) a partir de fragmentos delgados de folhas. Ciência e Agrotecnologia, v.29, p.575-581, 2005.

ESCALONA,M.; LORENZO, J.C.; GONZÁLEZ,B.; DAQUINTA, M.; GONZÁLEZ, J.L.; DESJARDINS, Y.; BORROTO, C.G. Pineapple (Ananas comosus (L.) Merr.) micropropagation in temporary immersion systems. Plant Cell Reports, v.18, p.743-748, 1999.

FERREIRA, D.P. Análises estatísticas por meio do SISVAR para windows: versão 4.0. In: REUNIÃO ANUAL DA REGIÃO BRASILEIRA DA SOCIEDADE INTERNACIONAL DE BIOMETRIA, 45., 2000. São Carlos. Anais. São Carlos: Ufscar, 2000. p.255-258.

FIROOZABADY, E.; GUTTERSON, N. Cost-effective in vitro propagation methods for pineapple. Plant Cell Reports, v.21, p.844-850, 2003.

FRÁGUAS, C.B.; PASQUAL, M.; PEREIRA, A.B. Multiplicação in vitro de Ficus carica L.: efeito da cinetina e do ácido giberélico. Ciência e Agrotecnologia, v.28, p.49-55, 2004.

GUERRA, M.P.; VESCO, L.L. dal; PESCADOR, R.; SCHUELTER, A.R.; NODARI, R.O. Estabelecimento de um protocolo regenerativo para micropropagação do abacaxizeiro. Pesquisa Agropecuária Brasileira, v.34, p.1557-1563, 1999.

MATHEWS, V.H.; RANGAN, T.S. Multiple plantlets in lateral bud and leaf explant in vitro cultures of pineapple. Scientia Horticulturae, v.11, p.319-328, 1979.
MURASHIGE, T.; SKOOG, F. A revised medium for rapid growth and bioassays with tobacco tissue cultures. Physiologia Plantarum, v.15, p.473-497, 1962.

PASQUAL, M.; HOSHIKA, E. Efeitos do ácido naftaleno acético e 6-benzilaminopurina sobre a proliferação in vitro de cactos Gymnocalycium baldianum e Mammillaria bocasana L. Pesquisa Agropecuária Brasileira, v.27, p.589-593, 1992.

REDIG, P.; SHAUL, O.; INZÉ, D.; VAN MONTAGU, M.; VAN ONCKELEN, H. Levels of endogenous cytokinins, indole-3-acetic acid and abscisic acid during cell cycle of synchronized tobacco BY-2 cells. FEBS Letters, v.391, p.175-180, 1996.

REINHARDT, D.H.R.C.; CUNHA, C.A.P. da. Métodos de propagação. In: CUNHA, G.A.P. da; CABRAL, J.R.S.; SOUZA, L.F. da S. O abacaxizeiro: cultivo, agroindústria e economia. Brasília: Embrapa Comunicação para Transferência de Tecnologia, 1999. p.105-138.

SAS INSTITUTE. SAS user's guide: statistic: version 6.12. Cary: SAS Institute, 1998. 846p.

SILVA, A.B. da; PASQUAL, M.; MACIEL, A.L. de R.; MOREIRA, M.A.; DUTRA, L.F. Influência da benzilaminopurina e do benomyl na proliferação in vitro de abacaxizeiro. Ciência e Agrotecnologia, v.26, p.1190-1196, 2002.

SKOOG, F.; MILLER, C.O. Chemical regulation of growth and organ formation in plant tissue cultured in vitro. Symposium of Society for Experimental Biology, v.11, p.118-131, 1957.

SOUZA, F.V.; SEREJO, J.A.S.; CABRAL, J.R.S. Beleza Rara. Cultivar, v.5, p.6-8, 2004.

TAMAKI, V.; MERCIER, H.; NIEVOLA, C.C. Cultivo in vitro de clones de Ananas comosus (L.) Merril. cultivar 'Smooth Cayenne' em diferentes concentrações de macronutrientes. Hoehnea, v.34, p.69-73, 2007.

VILlA, F.; ARAÚJO, A.G. de; PIO, L.A.S.; PASQUAL, M. Multiplicação in vitro da amoreira-preta 'Ebano' em diferentes concentrações de meio MS e BAP. Ciência e Agrotecnologia, v.20, p.582-589, 2005.

ZEPEDA, C.; SAGAWA, Y. In vitro propagation of pineapple. HortScience, v.16, p.495, 1981.

ZIV, M. Morphogenetic patterns of plant micropropagation in liquid medium in shaken flasks or large-scale bioreactor cultures. Israel Journal of Botany, v.40, p.145-153, 1991.

\footnotetext{
Recebido em 11 de março de 2008 e aprovado em 19 de agosto de 2008
} 